\title{
Digital Documentation of Maritime Cultural Heritage
}

\author{
Mohammad Said Salama \\ Alexandria Centre for Maritime Archaeology \& \\ Underwater Cultural Heritage, Faculty of Arts, \\ Alexandria University \\ El-Shatby, Alexandria, Egypt, 2017 \\ ms.salama2@gmail.com
}


Keywords: Underwater close-range Photogrammetry; Laser scanning; Cultural heritage documentation; Underwater Archaeology; Maritime Culture Heritage.

\section{Introduction}

Using digital technology for cultural heritage documentation is a global trend that has developed significantly in the 21 st century. Many important techniques are currently being used including 3D digital imaging, remote sensing and GIS (Geographic Information Systems). Digital documentation of Maritime heritage and archaeological objects and sites in their original sites and locations requires a powerful methodology able to capture and digitally model and document the geometric and appearance details of such sites. Digital recording and documentation within the aim of preservation are essential requirements as our cultural heritage suffers from on-going attritions, wars, natural disasters, climate changes and human negligence. Hence cultural heritage has received a lot of attention and benefits from the recent advances of range sensors and imaging devices $(\mathrm{Li}, 2008,527)$

\section{Context of the research}

highlighting the fundamental documentation principals for the maritime cultural heritage, for purposes of identification, protection, interpretation, and physical preservation of the maritime cultural 
heritage content which have been discussed and defined in the international charters, as the preservation of cultural properties passes on human knowledge, digital technology allows effective preservation of cultural properties and analysis and has become a trend all over the world.

In 2008, the 17th session of the General Assembly of International Council on Monuments and Sites (ICOMOS) adopted the Declaration of Quebec (Quebec Declaration) pointed out that:

"..in the protection and promotion of world heritage monuments and sites. It also calls upon a multidisciplinary approach and diversified sources of information in order to better understand, manage and conserve context...Considering that modern digital technologies (digital databases, websites) can be used efficiently and effectively at a low cost to develop multimedia inventories that integrate tangible and intangible elements of heritage, we strongly recommend their widespread use in order to better preserve, disseminate and promote heritage places and their spirit. These technologies facilitate the diversity and constant renewal of the documentation on the spirit of place."

Cultural heritage interpretation and presentation of the Charter (The ICOMOS Charter for the Interpretation and Presentation of Cultural Heritage Sites) also pointed out that:

"Develop technical and professional guidelines for heritage interpretation and presentation, including technologies, research, and training. Such guidelines 
must be appropriate and sustainable in their social contexts"

All of that highlights the importance of conserving, processing and presenting cultural heritage with digital technology.

Moreover, remote sensing technologies and methodologies for Cultural Heritage documentation and modelling allow the generation of very realistic digital results of plans, cross sections, and platforms that can be used for many purposes, such as historical documentation (El-Hakim, et al. 2007,199-220) , digital preservation and conservation, virtual reality/computer graphics applications , 3D repositories and catalogues, web-based geographic systems, computer-aided restoration, multimedia museum exhibitions and visualization (Manferdini. \&Remondino. 2010, 110-124).

Therefore, as documentation is a complex process that includes stages of data acquisition, interpretation, and production. Hence digital documentation includes several stages and incorporates as a prerequisite for the recording of the existing state and surroundings of the site by reports, drawings and photographs. Accordingly documentation is necessary for:

- Transmitting cultural heritage to next generations

- Utilizing sites in contemporary manner

- Obtaining correct data for future plans

- Determination of the problems affecting sites and their 
historical buildings or monuments

- Acquisition of knowledge about the history and the development of the archaeological sites (Yilmaz, et al. 2007, 428-433).

There are three major digital techniques for the archaeological documentation purposes:

1. "EDM" electronic distance measurements:

1. Total Station

2. Laser Scanner

3. GIS(Geographic Information System)

2. Image Base Systems

1. Digital close-range photogrammetry

3. Acoustics imagery systems

1. Side Scan Sonar

2. Sub-bottom profiling

3. Multi-beam sonar systems

4. ROVs \& AUVs

\section{1. "EDM" electronic distance measurement}

1. Total station: 


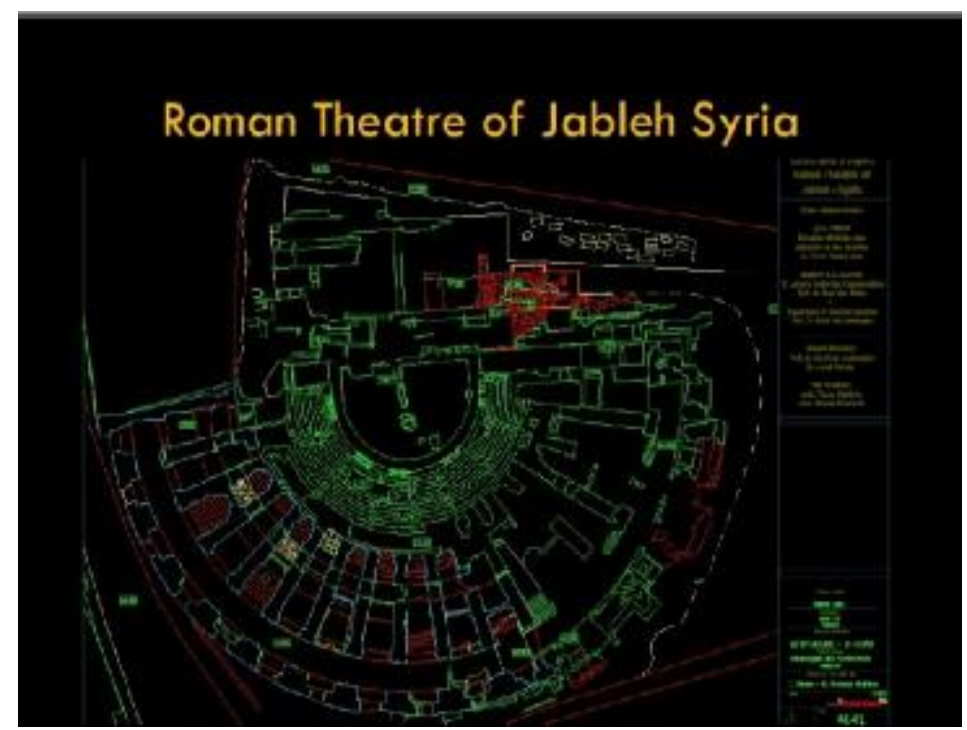

Figure 1figure 1w: The output data by the total station (Al-Muri, 2012)

A total station is an electronic/optical instrument used in modern surveying. It is an electronic theodolite (transit) integrated with an electronic distance meter (EDM) to read slope distances from the instrument to a particular point. The highest accuracy could be reached for the measured points $+/-2 \mathrm{~mm}$ (AlMurri, 2012).

\section{Laser scanner}

Terrestrial laser scanner devices represent one of the most widely investigated instruments in many fields of architectural and archaeological surveying applications. In order to allow photorealistic navigation and presentation of cultural heritage objects, 3D models with good geometric accuracy, large amount of details, different LOD (Level Of Detail) and high resolution textures are 
required (Boehler et al., 2002;Staiger, 2005).Since several years, laser scanning techniques are used for different purposes also in the framework of cultural heritage (Lichti. \& Gordon, 2004). However, the adapted versions of laser scanners for underwater archaeological sites still under development in order to apply the scanning for these sites with the same quality of measurements and accuracy.

Terrestrial laser data acquisition allows collecting a very huge amount of measurements with accuracy in the range of centimetres or even millimetres, which produces dense, accurate and detailed models.

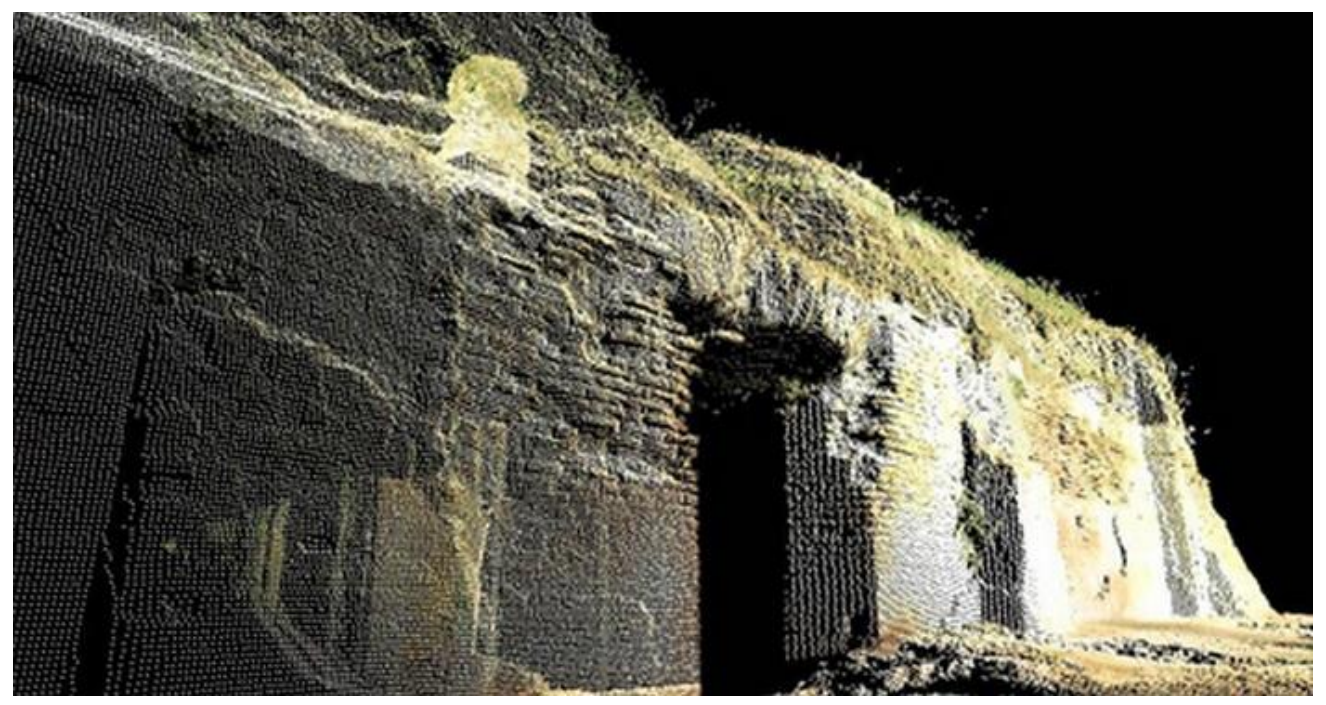

Figure 1: Point cloud laser scan dataset of the cistern complex of Portus, the principal port for the ancient city of Rome(http://www.portusproject.org) 


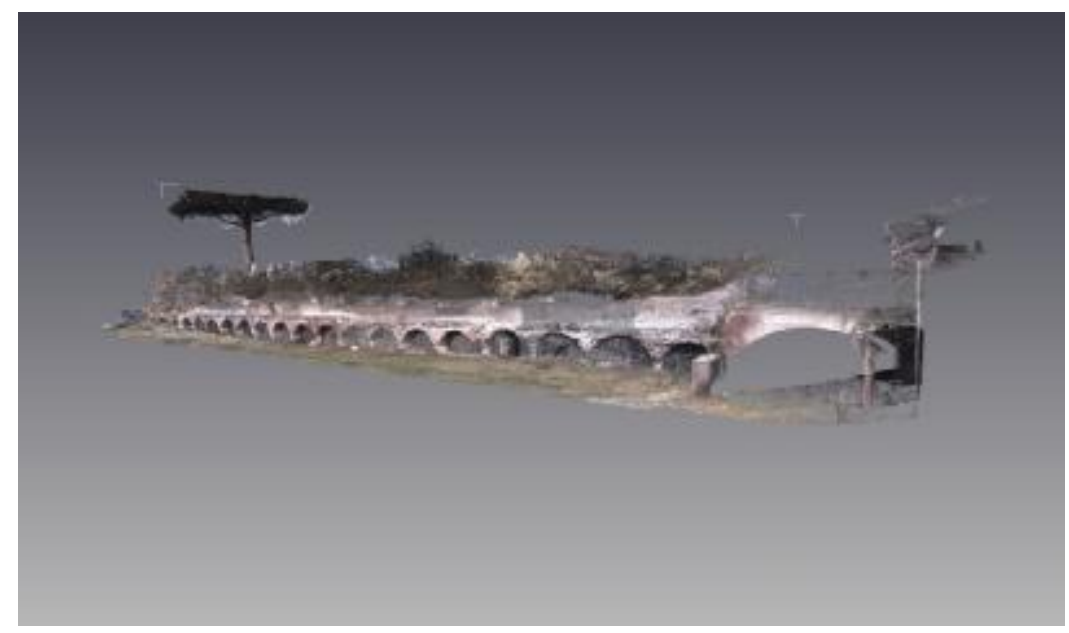

Figure 2: Point cloud laser scan dataset of the cistern complex of Portus, the principal port for the ancient city of Rome(http://www.portusproject.org)

\section{GIS (Geographic Information System)}

The term Geographic Information System ( GIS) and its synonym, is frequently applied to geographically oriented computer technology, integrated systems used in substantive applications to capture, store, manipulate, analyse, manage, and present all types of geographical data (Maguire, 1991). Geographic location is one of the most important attribute of any cultural heritage item especially when taking into account navigation support by mobile devices. The most valuable geographic description is in the form of digital geographic coordinates. Geographic coordinates are presented as $\mathrm{x}, \mathrm{y}$ and possibly $\mathrm{z}$-values which define a position in a coordinate system. Examples of coordinated systems are the system of latitude and longitude, used on the Earth's surface system. 
The added value of the geocoded cultural content is in the:

- Browsing cultural portals efficiently through space and time

- Searching for content in a more user friendly way, without the necessity of typing geographical names

- The possibility of discovering overlapping cultural content at the same location but originating from different sources and at different times

- Mapping of the content

- Performing of GIS calculations and simulations

- Defining the protected areas of monuments

- Geovisualisation and historical simulations (ATHENA WP7, 2011).

\section{Image Base Systems}

1. Digital close-range photogrammetry

Digital close-range photogrammetry is widely for underwater archaeological sites as the same as doing on land sites. It is the art and science of making measurements from photographs. Using calibrated digital/film Cameras to get 3D information with high accuracy output with accuracy 1:30000 (1mm in 30 meters) (Al Murri, 2012).

Digital close-range photogrammetry is used in:

1. Determining of historical and archaeological value of the sites.

2. Defining and obtaining measured drawing of the sites.

3. In preparation and application of conservation plans.

4. Determining deformation, evaluation of damage, 
analysis of the decay, deformation and anomalies

5. Making a site numerical by determining coordinates in architecture.(Yilmaz, 2007)

The most widespread usage of photogrammetry has been for the representation of the facades or elevations of historic buildings and structure. By improving digital techniques, digital close-range photogrammetry has become a more efficient and more economic method (Atkinson, 1996)

Photographic documentation records the present position of the site by photographs. Digital photography as analytical technology is advantageous because it shares the digital technology attributes of automation and provides time economy (Warden, 2005).

\section{Acoustics imagery systems}

1. Side Scan Sonar

Side scan sonar is a specialized system for detecting objects on the seafloor. Most side scan systems cannot provide depth information. Like other sonar's, side scan transmits sound energy and analyses the return signal (echo) that has bounced off the seafloor or other objects. Side scan sonar typically consists of three basic components: towfish, transmission cable, and topside processing unit. The strength of the return echo is continuously recorded, creating a "picture" of the ocean bottom. For example, 
objects that protrude from the bottom create a light area (strong return) and shadows from these objects are dark areas (little or no return), depending on operator preference. Side scan sonar is typically used in conjunction with a single beam or multi beam sonar system to meet full bottom coverage specifications for hydrographic surveys (www.nautial dhar ts. roaa. gov ).

2. Sub-bottom profiling

Sub-bottom profiling systems are employed to identify and characterize layers of sediment or rock under the seafloor. These systems also can be helpful in locating hard objects buried beneath the seafloor, such as shipwrecks. In sub-bottom profiling, a sound source directs a pulse toward the seafloor. Parts of this sound pulse reflect off of the seafloor, while other parts penetrate the seafloor. The portions of the sound pulse that penetrate the seafloor are both reflected and refracted as they pass into different layers of sediment. These signals return toward the surface, where they are detected by hydrophones towed by a surface vessel: The time it takes for the reflected sound pulses to return to the surface vessel can be used to determine the thickness of the sub-bottom layers in the seafloor and how the layers are positioned (e.g., level or sloped). The reflected sound also gives some limited information about the composition of the various layers refracted sound pulses, 
which follow a more complex path, provide additional information about the sub-bottom layers (substructure.com).

\section{Multi Beam -Sonar}

This system is widely used in hydrographic survey work and although excellent for logging the depth of large areas of seabed, it's under water archaeological applications are still uncertain. Multi beam-sonar systems provide fan-shaped coverage of the seafloor similar to side scan sonar, but the output data are in the form of depths rather echo, the multi beam system measures and records the time for the acoustic signal to travel from the transmitter (transducer) to the seabed(or object) and back to the receiver. Multi beam sonar's produce a "swath" of soundings (i.e., depths) to ensure full coverage of an area. The coverage area on the seafloor is dependent on the depth of the water, typically two to four times the water depth. 


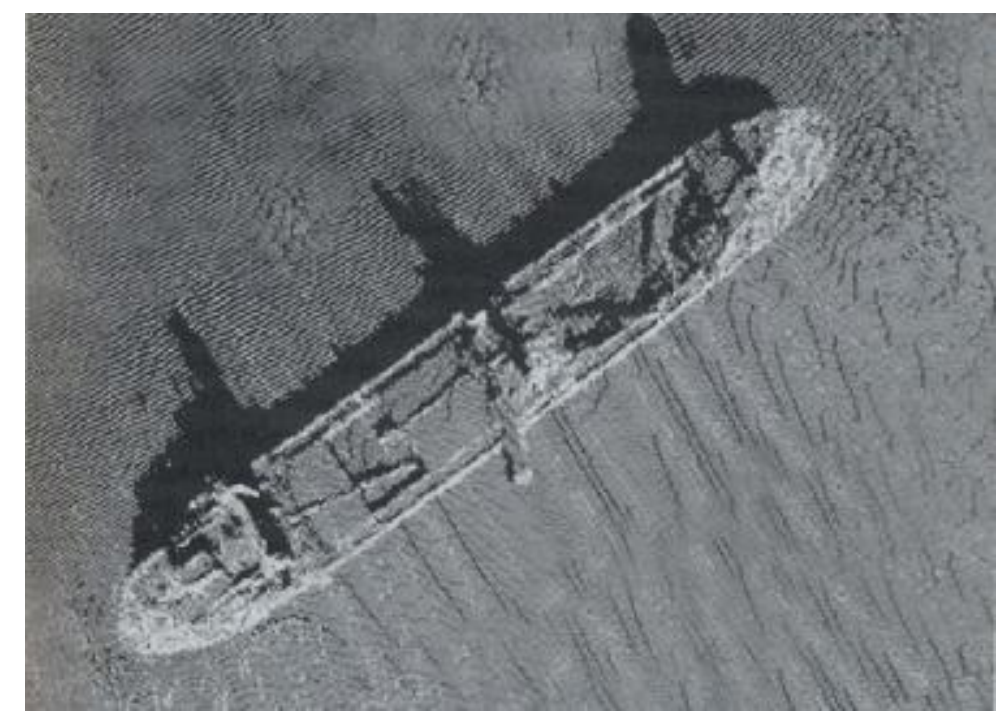

Figure 3: M ultibeam image of shipw reck in the PersianG ulf. D ata collected by R ESO N SeaB atM ultibeam System (G reen, 2004).

Recent advances with this system shows that it can locate large iron vessels but the operational range and its resolution are currently unclear. With a multi beam it is possible to generate a three dimensional image of the seabed which can used in software to analyse seabed features and create depth contour plots or alternatively image wreck sites. (Green, 2004p.75, 76).

3. ROVs (Remote Operated Vehicle) \& AUVs(autonomous underwater vehicle)

An AUV operates independently from the ship and has no connectig cabl es whereas ROVs are connected to an operator on the ship. AUV stands for autonomous underwater vehicle and is commonly known as unmanned underwater vehicle. AUVs can be used for underwater 
survey missions such as detecting and mapping submerged wrecks, rocks, and obstructions that can be a hazard to navigation for commercial and recreational vessels. An AUV conducts its survey mission without operator intervention. When a mission is complete, the AUV will return to a pre-programmed location where the data can be downloaded and processed. Underwater Survey has used ROVs with video cameras, to identify or classify objects detected by sonar when diver safety was in question or divers were not available. A remotely operated vehicle (ROV) is an unoccupied underwater robot that is connected to a ship by a series of cables. These cables transmit command and control signals between the operator and the ROV, allowing remote navigation of the vehicle. An ROV may include a video camera, lights, sonar systems, and an articulating arm. The articulating arm is used for retrieving small objects, cutting lines, or attaching lifting hooks to larger objects. While there are many uses for ROVs, some of the most common hydrographic applications include object identification (for submerged navigation hazards) and vessel hull inspections.

The varieties of digital technology used for documenting maritime archaeological sites does show that this technology achieves meaning when users are actively relating to the content and participating in the transformation of cultural heritage 
knowledge by way of digital tools. Many issues related to digital cultural heritage still have not been fully imagined, understood, or critically explored in relation to the communication and knowledge practices that are developing in the field (Cameron \&Kenderdine, 2007). 


\section{Conclusion:}

Cultural heritage protection is a key matter today worldwide.

There has been an increase in public awareness over recent years that these kinds of monuments constitute an important part of our past. There are innumerable cultural heritage sites all over the world. Preservation and documentation of these is an important matter. (Yilmaz 2007).

Digital documentation raises maritime cultural heritage as not being only an issue of definitions in museums and cultural heritage institutions, but of practices in all kinds of cultural heritage organisations and engaged private contributors that are involved in the field. Besides supporting new practices related to documentation, collection management and analysing of cultural historical texts, photos, objects, processes and places, the digital also brings new forms of collecting, categorising, understanding and reflecting upon cultural heritage.( Stuedahl, 2009, 67-81).

Thus, developing a documentation system for Egyptian maritime cultural heritage is a very urgent need, with the aid of the convenient technologies that will enhance the documentation process with the aim of preserving our maritime cultural heritage for the next generations. 


\section{References:}

[1] Al Murri, T. 2012.Digital Technologies of Documentation of cultural heritage, CULTNAT, p. 4.

[2] ATHENA WP7WorkingGroup"Development of plug-ins to be integrated within the European Digital Library"(ed). 2011. digital cultural content:guidelines for geographic information, Repro Stampa Ind. Grafica, Villa Adriana - Tivoli (Roma)http://www.athenaeurope.org/index.php?en/198/athenabooklets

[3] Atkinson, K. B. 1996. Close Range Photogrammetry and Machine Vision,WhittlesPublishing. Latheronwheel, Scotland, UK.

[4] Boehler, W., Heinz, G., \&Marbs, A. 2002.The potential of noncontact close range laser scanners for cultural heritage recording. International Archives of Photogrammetry Remote Sensing and Spatial Information Sciences, 34(5/C7), p. 430-436.

[5] Cameron, F. \&Kenderdine, s.(eds). 2007. Introduction. Theorizing Digital Cultural Heritage.A Critical Discourse.Cambridge, Mass: MIT Press.

[6] El-Hakim, S., Gonzo, L. Voltolini, F., Girardi, S., Rizzi, A., Remondino, F., Whiting, E., 2007: Detailed 3D modelling of castles. International Journal of Architectural Computing, Vol.5(2), pp. 199. 220.

[7] Goddio, F. 2007, Underwater Archaeology in the Canopic Region in Egypt

[8] The Topography and Excavation of Heracleion-Thonis and East Canopus (1996 - 2006)Oxford Centre for Maritime Archaeology, University of Oxford.

[9] Green, J. 2004, Maritime Archaeology A Technical Handbook second edition, Elsevier Academic press, UK. P.75-76.

[10] Li, Z., Chen, J., Baltsavias, E. 2008. Advances in Photogrammetry, Remote Sensing and Spatial Information Sciences; ISPRS Congress Book 2008; Taylor \&Francis Group: London, UK, p. 527.

[11] Lichti, D. Gordon, J. 2004. Error Propagation in Directly 
Georeferenced Terrestrial Laser Scanner Point Clouds for Cultural HeritageRecording. Proceedings of FIG Working Week 2004, Athens, Greece, May 22-27.

[12] MACHU Project .2008. MACHU Report(Managing Cultural Heritage Underwater). [Online] Available from:http://www.machuproject.eu/documenten/MACHU report 1.p df

[13] Maguire, D. J. 1991. An overview and definition of GIS. Geographical Information Systems: principles and applications, 1, 9-20.

[14] Manferdini, A. M., Remondino, F. 2010. Reality-based 3Dmodeling, segmentation and web-based visualization.Ioannides, M , Fellner, D., Georgopoulos, A., Hadjimitsis, D., 2010. Digital Heritage: Third International Euro-Mediterranean Conference, EuroMed 2010, Lemessos, Cyprus, November 8 13, 2010. Proceedings, (pp. 110-124). Springer Berlin Heidelberg.

[15] Staiger, R. 2005. The Geometrical Quality of Terrestrial Laser Scanner (TLS).Proceedings of Pharaohs to GeoinformaticsFIGWorking Week 2005 and GSDI-8 Cairo, Egypt, April 16-21, 2005. http://www.fig.net/pub/cairo/abstracts/ts 38/ts38 05 staiger abs.pdf

[16] Stuedahl, D. (2009). Digital Cultural Heritage Engagement: A New Research Field for Ethnology. Ethnologiascandinavica, 39, 67-81.

[17] Warden, R. Woodcock, D. 2005.Historic documentation: a model of projectbased learning for architectural education, Landscape and Urban Planning, 73(2-3), p.110-119.

[18] Yilmaz, H. M., Yakar, M., Gulec, S. A., \&Dulgerler, O. N. 2007.Importance of digital close-range photogrammetry in documentation of cultural heritage.Journal of Cultural Heritage, 8(4), p.428-433.

[19] NOAA Ocean Facts, [Online], 2013. Available: http://oceanservice.noaa.gov/facts/auv-rov.html

[20] http://www.nauticalcharts.noaa.gov/hsd/SSS.html 
[21] http://substructure.com/about/marine-services-

information/hydrographic-surveys/tools-used-to-examine-the-areabelow-the-seafloor

[22] http://www.whoi.edu/sbl/liteSite.do?litesiteid=2740\&articleId=4 418 